\title{
BMJ Open Sex differences in the 1-year risk of dying following all-cause and cause-specific hospital admission after age 50 in comparison with a general and non- hospitalised population: a register-based cohort study of the Danish population
}

\author{
Andreas Höhn, ${ }^{1,2}$ Lisbeth Aagaard Larsen, ${ }^{2}$ Daniel Christoph Schneider, ${ }^{1}$ \\ Rune Lindahl-Jacobsen, ${ }^{2}$ Roland Rau, ${ }^{1,3}$ Kaare Christensen, ${ }^{2,4}$ Anna Oksuzyan ${ }^{1}$
}

To cite: Höhn A, Larsen LA, Schneider DC, et al. Sex differences in the 1-year risk of dying following allcause and cause-specific hospital admission after age 50 in comparison with a general and non-hospitalised population: a register-based cohort study of the Danish population. BMJ Open 2018;8:e021813. doi:10.1136/ bmjopen-2018-021813

- Prepublication history and additional material for this paper are available online. To view these files, please visit the journal online (http://dx.doi. org/10.1136/bmjopen-2018021813).

Received 23 January 2018 Revised 3 May 2018 Accepted 7 June 2018

Check for updates

(c) Author(s) (or their employer(s)) 2018. Re-use permitted under CC BY-NC. No commercial re-use. See rights and permissions. Published by BMJ.

For numbered affiliations see end of article.

Correspondence to

Andreas Höhn;

hoehn@demogr.mpg.de

\section{ABSTRACT}

Objectives We examine the mortality of men and women within the first year after all-cause and cause-specific hospital admission to investigate whether the sex differences in mortality after hospitalisation are higher than in the corresponding general and non-hospitalised population.

Design This is a population-based, longitudinal study with nationwide coverage. The study population was identified by linking the National Patient Register with the Central Population Register using a 5\% random sample of the Danish population.

Setting The population born between 1898 and 1961, who was alive and residing in Denmark after 1977, was followed up between 1977 and 2011 with respect to hospital admissions and mortality while aged 50-79. Primary outcome measures The absolute sex differences in the 1-year risk of dying after all-cause and cause-specific hospital admission. The hospitalised population sex differentials were then compared with the sex differences in a general and a non-hospitalised population, randomly matched by age, sex and hospitalisation status.

Results The risk of dying was consistently higher for hospitalised men and women. At all ages, the absolute sex differences in mortality were largest in the hospitalised population, were smaller in the general population and were smallest in the non-hospitalised population. This pattern was consistent across all-cause admissions, and with respect to admissions for neoplasms, circulatory diseases and respiratory diseases. For all-cause hospital admissions, absolute sex differences in the 1-year risk of dying resulted in 43.8 excess male deaths per 1,000 individuals within the age range 50-79, while the levels were lower in the general and the non-hospitalised population, at levels of 13.5 and 6.6, respectively. Conclusions This study indicates a larger male disadvantage in mortality following hospitalisation, pointing towards an association between the health status of a population and the magnitude of the female advantage in mortality.

\section{Strengths and limitations of this study}

- This study uses high-quality Danish register data, with nationwide coverage, that leave little room for selection bias due to non-response or loss to follow-up.

- Our findings of excess male mortality within the first year after all-cause hospitalisation compared with their female counterparts remain robust when stratifying by the main causes of admission to hospital in Denmark

- Due to a lack of further medical data on the admissions, including information on risk factors and severity of diseases, we were not able to disentangle the potential behavioural and biological mechanisms behind widening sex differences after hospitalisation.

\section{BACKGROUND}

Empirical studies have consistently reported that women have a mortality advantage at all ages, starting at infancy and extending over the entire life course. ${ }^{1}$ Women have lower rates of mortality than men for nearly all causes of death, including most cancers, ${ }^{2-4}$ respiratory diseases ${ }^{56}$ and accidents. ${ }^{7}$ Moreover, the female advantage in mortality persists even after stressful events during the life course, such as bereavement ${ }^{89}$ or famines and epidemics. ${ }^{10}$ While the relative sex differences in mortality peak at around age 25 and tend to become smaller with age, ${ }^{11}$ the absolute sex differences grow almost exponentially between ages 40 and 90 , as general levels of mortality increase. ${ }^{12}$ Thus, in recent decades, the largest share of the sex differences in life expectancy has been attributed to mortality differentials after the age of 
$50^{13}$ — when individuals start to accumulate disease and disabilities, and the incidence of most adverse health conditions increases. ${ }^{14}$

A number of previous studies have argued that a hospital admission may serve as a quasi-objective indicator of health. An admission to the hospital may indicate the onset of a health decline or the manifestation of a health decline that started long ago that now requires extensive medical interventions. ${ }^{15-17}$ The use of hospitalisation as a proxy for health is supported by previous research findings showing that adults of all ages who rate their health and their quality of life as poor are at an increased risk of hospital admission. ${ }^{18-21}$ Furthermore, the well-established associations between major risk factors and the increased risk of dying from certain causes, such as smoking and lung cancer, have also been found for the relationship between risk factors and cause-specific reasons of admission. ${ }^{22-24}$ Empirical findings have demonstrated that smoking, ${ }^{22}$ hazardous drinking, ${ }^{25}$ being overweight, ${ }^{26}$ having high cholesterol levels ${ }^{27}$ and a lack of physical activity $^{28}$ are related to an increased risk of hospital admission. The presence of multiple risk factors has been found to be especially strongly associated with a high risk of admission. ${ }^{29}$

Although it has been well established that women have a mortality advantage across all ages and all causes of death, it is not yet known whether this advantage changes after the manifestation of bad health, which we measure as a hospital admission. To answer this question, we estimate the absolute sex differences in the 1-year risk of dying after all-cause and cause-specific hospital admission as an inpatient. We compare these absolute sex differentials with the corresponding differences we would have observed in the general and the non-hospitalised population.

\section{METHODS AND MATERIALS \\ Data}

This study uses a 5\% random sample of the Danish population. Using the unique personal identification number that is assigned to all individuals residing in Denmark, ${ }^{30}$ we linked records from the National Patient Register (NPR) with data of the Central Population Registry (CPR). The CPR, which covers the entire population alive and residing in Denmark since 1968, contains information on each resident's vital status, sex and place and date of birth. ${ }^{31}$ The NPR is a population-based register with nationwide coverage that contains information on all admissions to hospitals since $1977 .^{32}$ As reports to the administration are compulsory, the NPR data have high levels of completeness and reliability, making these data an excellent tool for research. ${ }^{33}$ Whereas data on hospitalisations are available for the period 1977-2011, the vital status of individuals was traceable up to the year 2013. In the NPR, diagnoses were classified in accordance with the International Classification of Diseases (ICD), 8th Revision until 1993 and the ICD 10th Revision starting in $1994 .{ }^{34}$ We classified the causes of admission to hospital according to the main chapters and using broad groups to reduce the potential bias, which may emerge from combining two systems of classification. An overview of the coding is given in online supplementary table $1-\mathrm{S}$.

\section{Study population}

We identified all individuals who were born between 1 January 1898 and 31 December 1961, who were alive and who resided in Denmark after 1968 in the 5\% random sample $(n=214,613)$. Of those, we then selected all individuals who survived up to age 50 and resided in Denmark after 1 January $1977(n=198,580)$. Out of all remaining individuals, $64.3 \%(\mathrm{n}=127,642)$ of the sample had been admitted to the hospital at least once between 1 January 1977 and 31 December 2011. Hospitalisation was defined as the first time an individual was admitted to the hospital while aged 50-79 as an inpatient, for at least one night and for any reason between the years 1977 and 2011. Subsequent admissions and admissions that occurred among these individuals before the age of 50, after age 79 and before 1977—for the same or other causes-were not taken into account.

To examine whether the sex differences in mortality increase following an admission to hospital, we compared the sex differentials after hospitalisation with the corresponding differences measured among two healthier references. For this purpose, two matched populations aged 50-79 were selected randomly from the study sample: one group to represent the general population, and the other group to represent the non-hospitalised population. Each hospitalised individual was matched to one individual from each reference group. The matched individuals forming the two reference populations had to be the same age $(+/-30$ days $)$, the same sex and alive on the day the corresponding case was hospitalised. Whereas the individuals representing the general population were selected irrespective of hospitalisation status, the individuals representing the non-hospitalised population had not been hospitalised within a concordant year before and after the exact date the corresponding case was admitted to the hospital, irrespective of the case's cause of admission. Cases and matches were drawn from the same source population. We used matching with replacement to correct the observed distortion that a certain proportion of the hospitalised population would have remained without a match, which emerged when matching without replacement was tested. The matching was carried out 100 times to increase the robustness of the matching results, and to bypass the need to choose a single matching scenario. Consequently, the same person may appear more than once in each of the 100 matching scenarios.

\section{Patient and public involvement}

No patients were involved in setting the research question or the outcome measures, nor were they involved in developing plans for design or implementation of the study. No patients were asked to advise on interpretation 
or writing up of results. No patients were involved in the recruitment to and conduct of the study. There are no plans to disseminate the results of the research to study participants or the relevant patient community.

\section{Statistical analysis}

The survival time of the hospitalised individuals starts immediately with the day of the first all-cause hospital admission after age 50, which was recorded in the registers. No lag time or washout period was used to ensure that the immediate impact of the manifestation of bad health on the risk of dying was captured, implying that deaths during the index hospital stay are included in the mortality calculations. Analogously, the process time of the individuals of both reference populations starts on the day the corresponding case was hospitalised. The survival status of all individuals was followed up within 1 year. If a person was alive by the end of the follow-up period or had migrated, this individual was considered as having no event. We used a generalised additive model (GAM) for binary data with a logit link. Unlike in generalised linear models, the linear predictor in the GAM is replaced by a sum of smoothing functions. ${ }^{35} 36$ We used penalised B-splines, so-called P-splines, as basis functions in the regression to smooth over age. ${ }^{37}{ }^{38} \mathrm{We}$ modelled the age-specific 1-year risk of dying separately for the men and the women of each population by single years of age. For the hospitalised population, we further estimated separate models by cause of admission to hospital to investigate whether the female advantage in survival following hospitalisation varies across different causes of admission. While the data preparation and the merging of registries was carried out with STATA (V.15), all statistical analyses were performed in R (V.3.3.2).

\section{RESULTS}

Of the 127,642 individuals who were hospitalised, $49.9 \%$ $(\mathrm{n}=63,649)$ were men and $50.1 \% \quad(\mathrm{n}=63,993)$ were women. The mean age at hospitalisation was slightly lower among the men $(61.7 ; \mathrm{SD}=8.5)$ than among the women $(62.0 ; \mathrm{SD}=9.0)$. An overview on the causes of admission to hospital is provided in table 1 . We found the distribution of causes of hospital admission to be different in men and in women. In comparison with men, women were more likely to be hospitalised due to neoplasms, diseases of the blood and blood-forming organs, endocrine, nutritional and metabolic diseases, diseases of the eye and adnexa, musculoskeletal disorders and diseases of the genitourinary system. In contrast, more men were admitted due to ischaemic heart diseases, cerebrovascular diseases and other circulatory diseases, as well as due to respiratory and digestive diseases than women. We found only small sex differences in the distribution with respect to infectious and parasitic diseases, mental and behavioural

Table 1 Overview of causes of admission to hospital by sex

\begin{tabular}{|c|c|c|c|c|}
\hline \multirow[b]{2}{*}{ Cause of hospital admission } & \multicolumn{2}{|l|}{ Men } & \multicolumn{2}{|l|}{ Women } \\
\hline & Number & Share in \% & Number & Share in \% \\
\hline Infectious and parasitic diseases & 980 & 1.54 & 1,012 & 1.58 \\
\hline Neoplasms & 6,625 & 10.41 & 9,310 & 14.55 \\
\hline Diseases of the blood and blood-forming organs & 266 & 0.42 & 401 & 0.63 \\
\hline Endocrine, nutritional and metabolic diseases & 1,368 & 2.15 & 2,220 & 3.47 \\
\hline Mental and behavioural disorders & 1,000 & 1.57 & 883 & 1.38 \\
\hline Diseases of the nervous system & 1,434 & 2.25 & 1,382 & 2.16 \\
\hline Diseases of the eye and adnexa & 1,026 & 1.61 & 1,464 & 2.29 \\
\hline Diseases of the ear and mastoid process & 461 & 0.72 & 496 & 0.78 \\
\hline Ischaemic heart diseases & 5,899 & 9.27 & 2,601 & 4.06 \\
\hline Cerebrovascular diseases & 2,386 & 3.75 & 1,756 & 2.74 \\
\hline Other circulatory diseases & 6,324 & 9.94 & 5,368 & 8.39 \\
\hline Respiratory diseases & 3,785 & 5.95 & 3,233 & 5.05 \\
\hline Digestive diseases & 8,368 & 13.15 & 6,166 & 9.64 \\
\hline Diseases of the skin and subcutaneous tissue & 786 & 1.23 & 700 & 1.09 \\
\hline Musculoskeletal disorders & 4,737 & 7.44 & 5,858 & 9.15 \\
\hline Diseases of the genitourinary system & 4,680 & 7.35 & 6,968 & 10.89 \\
\hline Injuries, poisonings and accidents & 6,466 & 10.16 & 7,228 & 11.29 \\
\hline All other diseases* & 7,058 & 11.09 & 6,947 & 10.86 \\
\hline Total & 63,649 & 100.00 & 63,993 & 100.00 \\
\hline
\end{tabular}

*The largest groups among the category of all other diseases are symptoms, signs and abnormal clinical and laboratory findings (men: $57.57 \%$, women: $58.42 \%$ ) and factors influencing the health status and contact with health services (men: $37.47 \%$, women: $36.99 \%$ ). 
Table 2 Number of individuals, number of deaths and the risk of dying within 1 year of follow-up by sex and age in the hospitalised, general and non-hospitalised population

\begin{tabular}{|c|c|c|c|c|c|c|c|c|}
\hline \multirow{3}{*}{$\begin{array}{l}\text { Age at hospital } \\
\text { admission/age of } \\
\text { matches }\end{array}$} & \multicolumn{4}{|l|}{ Men } & \multicolumn{4}{|l|}{ Women } \\
\hline & \multicolumn{2}{|c|}{ Individuals } & \multicolumn{2}{|c|}{ Deaths } & \multicolumn{2}{|c|}{ Individuals } & \multicolumn{2}{|c|}{ Deaths } \\
\hline & No. & Share in $\%$ & No. & Risk in \% & No. & Share in $\%$ & No. & Risk in \% \\
\hline \multicolumn{9}{|c|}{ Hospitalised population } \\
\hline $50-54$ & 18,397 & 28.90 & 906 & 4.92 & 19,569 & 30.58 & 622 & 3.18 \\
\hline $55-59$ & 12,392 & 19.47 & 898 & 7.25 & 11,432 & 17.86 & 514 & 4.50 \\
\hline $60-64$ & 10,493 & 16.49 & 1,074 & 10.24 & 9,244 & 14.45 & 655 & 7.09 \\
\hline $65-69$ & 9,030 & 14.19 & 1,320 & 14.62 & 8,508 & 13.30 & 844 & 9.92 \\
\hline $70-74$ & 7,623 & 11.98 & 1,432 & 18.79 & 7,967 & 12.45 & 1,046 & 13.13 \\
\hline $75-79$ & 5,714 & 8.98 & 1,457 & 25.50 & 7,273 & 11.37 & 1,261 & 17.34 \\
\hline Total & 63,649 & 100.00 & 7,087 & 11.13 & 63,993 & 100.00 & 4,942 & 7.72 \\
\hline \multicolumn{9}{|l|}{ General population* } \\
\hline $50-54$ & 18,400 & 28.91 & 124 & 0.68 & 19,558 & 30.56 & 88 & 0.45 \\
\hline $55-59$ & 12,394 & 19.47 & 145 & 1.17 & 11,452 & 17.90 & 80 & 0.70 \\
\hline $60-64$ & 10,486 & 16.47 & 195 & 1.86 & 9,231 & 14.43 & 100 & 1.08 \\
\hline $65-69$ & 9,042 & 14.21 & 268 & 2.97 & 8,520 & 13.31 & 153 & 1.80 \\
\hline $70-74$ & 7,612 & 11.96 & 369 & 4.85 & 7,961 & 12.44 & 218 & 2.74 \\
\hline $75-79$ & 5,714 & 8.98 & 449 & 7.85 & 7,270 & 11.36 & 334 & 4.60 \\
\hline Total & 63,649 & 100.00 & 1,551 & 2.44 & 63,993 & 100.00 & 974 & 1.52 \\
\hline \multicolumn{9}{|c|}{ Non-hospitalised population* } \\
\hline $50-54$ & 18,400 & 28.91 & 57 & 0.31 & 19,558 & 30.56 & 27 & 0.14 \\
\hline $55-59$ & 12,393 & 19.47 & 53 & 0.43 & 11,452 & 17.90 & 21 & 0.18 \\
\hline $60-64$ & 10,488 & 16.48 & 76 & 0.72 & 9,232 & 14.43 & 32 & 0.34 \\
\hline $65-69$ & 9,042 & 14.21 & 108 & 1.20 & 8,521 & 13.32 & 52 & 0.61 \\
\hline $70-74$ & 7,612 & 11.96 & 150 & 1.97 & 7,958 & 12.44 & 83 & 1.05 \\
\hline $75-79$ & 5,713 & 8.98 & 150 & 2.63 & 7,271 & 11.36 & 154 & 2.12 \\
\hline Total & 63,649 & 100.00 & 656 & 1.03 & 63,993 & 100.00 & 369 & 0.58 \\
\hline
\end{tabular}

*The number of deaths and the risk of dying refers to the average of 100 matching results.

disorders, diseases of the nervous system, diseases of the ear and mastoid process, diseases of the skin and subcutaneous tissue as well as injuries, poisonings and accidents.

An overview of the three populations is given in table 2. While the data for the hospitalised population represent the exact number of observed cases, the numbers for the general and the non-hospitalised population refer to the mean of 100 matched samples. Because the matched individuals were of the same age and the same sex as the corresponding cases, the three populations had identical age structures (mean=61.9, $\mathrm{SD}=8.9$ ) and sex ratios. We found that the risk of dying was highest among the men and the women of the hospitalised population at the level of $9.42 \%$ (95\% CI 9.26\% to $9.58 \%$ ). The risk of dying was substantially lower and at the level of $1.98 \%$ (95\% CI $1.90 \%$ to $2.05 \%$ ) in the corresponding general population, and lowest among the non-hospitalised population at a level of $0.80 \%$ (95\% CI $0.75 \%$ to $0.85 \%$ ), respectively. As shown in table 2 , men had consistently higher mortality than women in all of the three populations. In all populations, we found the mortality of both sexes to increase consistently with age.

We further estimated the risk of dying and the trajectory of this risk by single years of age for men and women in each population and corresponding $95 \%$ CI using a non-parametric GAM. As shown in figure 1, we found that men had consistently higher mortality than their female counterparts in each population, at all ages and for admissions due to all causes, neoplasms, circulatory and respiratory diseases. The risk of dying increased consistently with age among the men and the women in each population, and with respect to all causes of admission to hospital

At the age of 50, the 1-year risk of dying for all-cause admissions in the hospitalised population was $5.17 \%$ (95\% CI $4.60 \%$ to $5.73 \%$ ) for men and $2.97 \%$ (95\% CI $2.66 \%$ to $3.29 \%$ ) for women. With age, the risk of dying increased and reached a level of $26.61 \%$ (95\% CI $24.08 \%$ to $29.13 \%$ ) and $19.12 \%$ (95\% CI $17.65 \%$ to $20.60 \%$ ) 


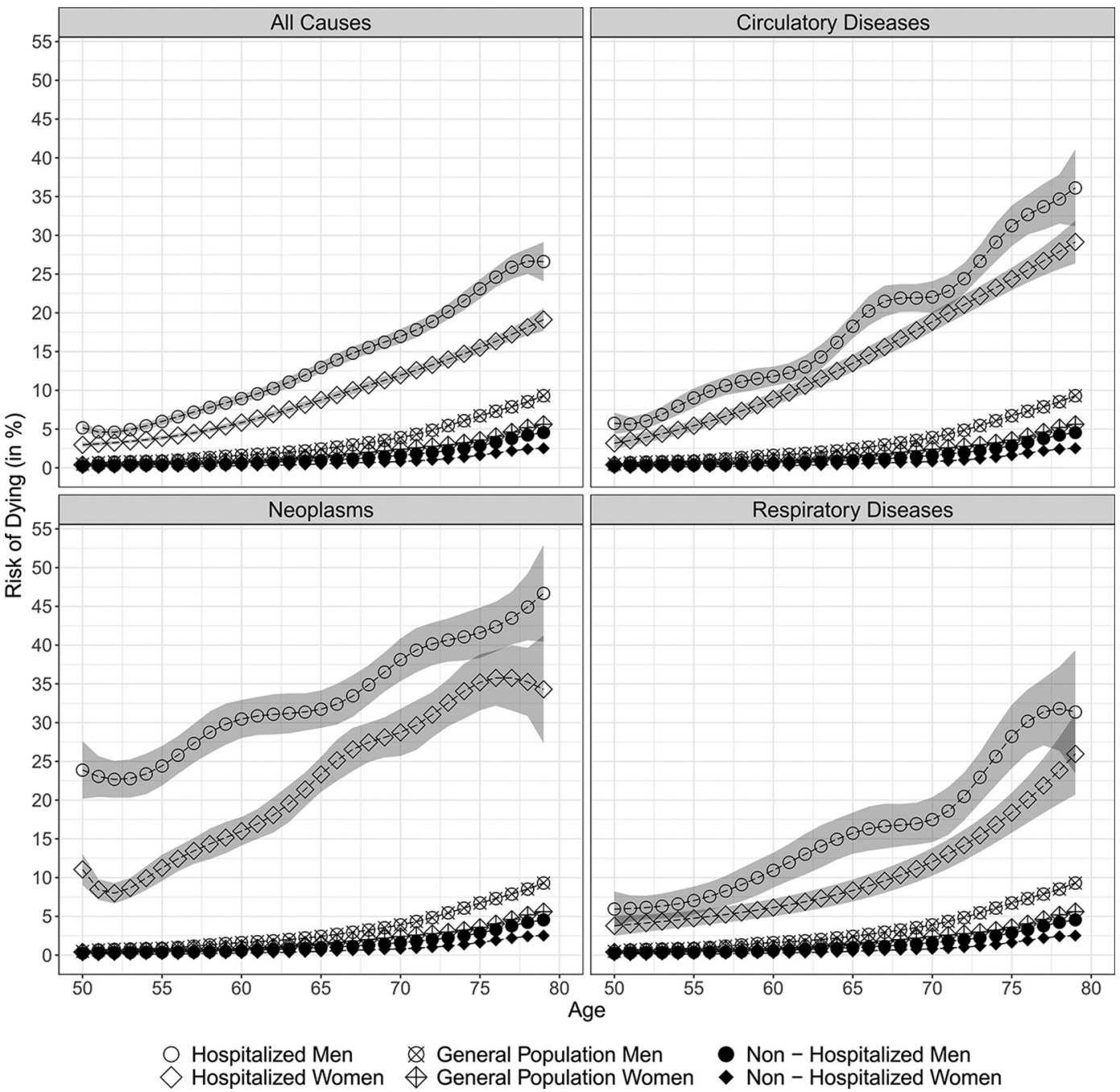

Figure 1 Estimated age trajectories in the risk of dying within 1 year of follow-up by cause of admission to hospital.

among 79-year-old men and women of the hospitalised population, respectively.

We found the absolute increase in mortality with age to be smaller in the general population than in the hospitalised population. Starting with levels of $0.47 \%$ (95\% CI $0.46 \%$ to $0.49 \%)$ among men and $0.39 \%$ (95\% CI $0.38 \%$ to $0.41 \%$ ) among women at age 50 , the risk of dying was $9.30 \%$ (95\% CI $9.12 \%$ to $9.47 \%$ ) and $5.61 \%$ (95\% CI $5.49 \%$ to $5.73 \%$ ) at the age of 79 in the general population, respectively.

We found the non-hospitalised population to have the lowest absolute increase in mortality with age: at age 50 , the risk of dying was $0.25 \%$ (95\% CI $0.24 \%$ to $0.26 \%$ ) for men and $0.12 \%(95 \%$ CI $0.11 \%$ to $0.13 \%$ ) for women, and it increased to $4.54 \%$ (95\% CI $4.42 \%$ to $4.67 \%$ ) and $2.52 \%$ (95\% CI $2.43 \%$ to $2.60 \%$ ) at age 79 , respectively.

In a next step, we calculated the absolute sex differences in the 1-year risk of dying and the the male excess mortality per 1,000 persons. Figure 2 shows the age trajectory of the male excess mortality in each of the three populations and by cause of admission to hospital. At all ages and regarding admissions for all causes, neoplasms, circulatory and respiratory diseases, the absolute sex differences were largest in the hospitalised population, were smaller in the general population, and were smallest in the non-hospitalised population. At age 50 and for all-cause admissions, the sex differences in survival resulted in 22.0 excess male deaths per 1,000 individuals in the hospitalised population, while there were 0.8 excess male deaths in the general population and 1.3 excess male deaths in the non-hospitalised population. Within the observed age range, the excess male mortality increased almost steadily among all three populations, resulting at levels of 42.0, 9.8 and 4.8 excess male deaths per 1,000 individuals at age 65, and levels of 74.8, 36.9 and 20.3 at age 79 , respectively. For all-cause hospital admissions, the larger absolute sex differences in the 1 -year risk of dying resulted, on average, in 43.8 excess male deaths per 1000 individuals within the age range 50-79, while the levels were lower in the general and the non-hospitalised population, and at levels of 13.5 and 6.6 , respectively. While the male excess mortality after all-cause hospital admission increases steadily with age, the pattern differs when broken down by specific causes of admission. Whereas for admissions due to circulatory and respiratory diseases the male excess mortality shows 


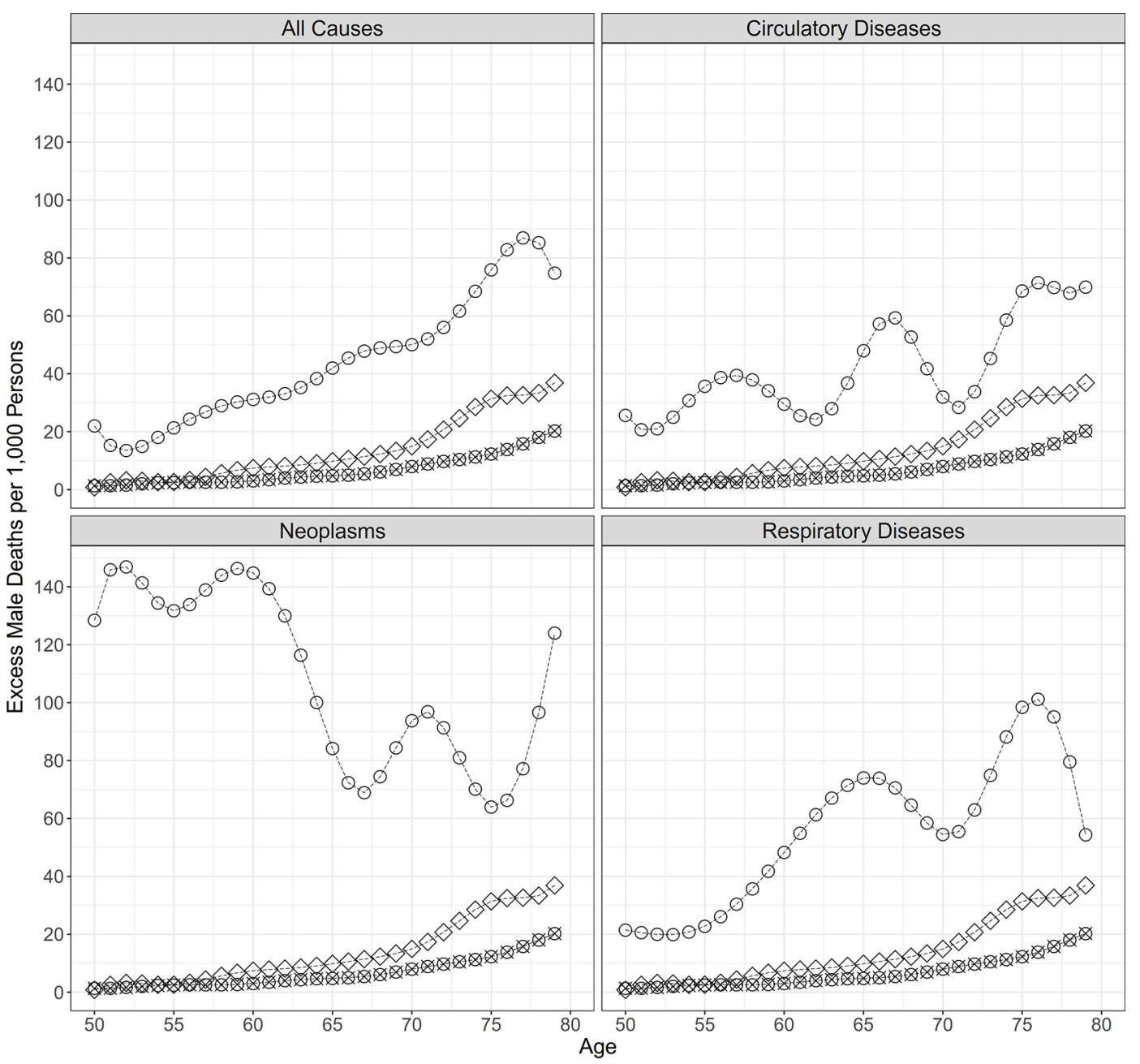

$\bigcirc$ Hospitalized Population $\diamond$ General Population $\otimes$ Non - Hospitalized Population

Figure 2 Male excess mortality within 1 year of follow-up by cause of admission to hospital.

a similar increasing pattern, the male excess mortality is highest at younger ages for admissions due to neoplasms and decreases with age.

\section{DISCUSSION}

In this study, we investigated how women's mortality advantage changes after the manifestation of an adverse health condition, which we measured as a hospital admission. We estimated the absolute sex differences in the 1-year risk of dying after an all-cause and cause-specific hospitalisation among the population aged 50-79, and compared these patterns with those observed in a matched general and non-hospitalised population. As expected, women had consistently lower mortality than men in all three populations. In addition, we found that the absolute sex differences in mortality were highest for the hospitalised population, were lower in the general population and were lowest in the non-hospitalised population. The excess of male mortality always remained larger in the hospitalised population also when differentiating by cause of admission to hospital.

\section{Strengths and weaknesses of the study}

In this study, we used Danish register data, which provide nationwide coverage and are representative of the total Danish population. In contrast to longitudinal survey data, these register data suffer less in terms of non-response and loss to follow-up; issues that could have biased the analyses and led to skewed results. ${ }^{39}$ Another strength is that we were able to examine mortality for the overarching all-cause hospital admissions as well as the mortality patterns for cause-specific hospital admissions. This allowed us to establish if the larger male excess mortality following hospitalisation was present across different causes of hospital admission, representing admissions for the major causes of death in Denmark. Similar patterns of sex differences in all-cause and cause-specific admissions suggest that the larger sex differences in mortality after hospital admission cannot be fully explained by differences in the distribution of causes of admission among men and women. In order to minimise the bias due to changes in ICD coding over the study period, we used broad categories to group causes of hospital admission. 
We calculated the absolute sex differences in the 1-year risk of dying after an admission to hospital. This allowed us to directly compare the male excess mortality in the hospitalised, the general and the non-hospitalised population. It has been shown that different conclusions about health inequalities might be the result of the effect measure used. This has been shown in relation to mortality differences between socioeconomic groups, across countries, over time ${ }^{40}$ and in respect to sex differences. ${ }^{12} 41$ We therefore replicated the analysis using risk ratios (see online supplementary figure $1-S$ ). Using risk ratios leads to a different interpretation, that the sex differences were lowest among the hospitalised individuals and highest for the non-hospitalised population where the overall risk of mortality was lowest. Both, absolute and relative measures are context dependent and their use needs to be justified. ${ }^{40}$ Problems surrounding the interpretation of risk ratios often appear when populations under investigation differ in their overall risks of mortality. ${ }^{12} \mathrm{In}$ our case, the discrepancy between absolute and relative measures is driven by the fact that the three populations differ significantly in their initial levels of mortality. As we are interested in quantifying the burden of the male excess mortality across the three populations, an absolute measure appears to be most suitable as it takes into account the underlying risks of mortality. ${ }^{42}$

Our study does not address the underlying reasons for the greater excess male mortality in the 1-year period after admission to hospital. The register data did not allow us to examine the severity of the underlying causes of hospital admission and to control for differences in health behaviours. Furthermore, the study design did not allow us to examine the question of whether the observed gaps in survival after hospital admission changed over time or across cohorts. This issue may be particularly relevant for Denmark where the sex differentials in mortality are known to have been affected by a stagnation of female life expectancy during the 1977-1995 period, which was a consequence of smoking among women born between the two World Wars. ${ }^{43-45}$ The increased prevalence of smoking among Danish women, when compared with countries where the prevalence of female smokers remained low throughout the 20th century, may have an impact on our findings in two ways. First, by leading to higher levels of mortality among women of all three populations. Second, by leading to higher rates of admissions for smoking-related diseases among women. Likely, the male excess mortality would have been higher in all three populations in the absence of higher smoking rates among Danish women. The data do not allow us to quantify the impact of the Danish smoking phenomenon on our findings. All in all, this demonstrates that factors which determine the distribution of causes of admission to hospital and the levels of disease-specific mortality after hospitalisation within a population are complex. Both factors may be influenced by changes in the organisation and the performance of the healthcare system, including shifts in the admission strategies and the quality of medical treatment; or they could depend on a range of demographic characteristics, such as the prevalence of diseases or the distribution of risk factors in a population. ${ }^{22}$

It is important to highlight that our analysis compares men and women of the same age and does not control for the health status of individuals. However, we recognise that men tend to develop adverse health conditions at earlier ages than women, ${ }^{46} 47$ and that studies on strokes and myocardial infarctions have shown that, on average, men are 8 years younger than women at the onset of these conditions. ${ }^{4-51}$

To gain a deeper understanding of the sex differences in mortality after hospital admission, future research should aim to identify the underlying reasons for these differences, and investigate how these sex disparities have developed over time, by cohort, and how they vary by socioeconomic status. Also, the length of follow-up we used needs to be taken into account. It could be that the increased level of mortality during the first year after admission is temporary and that the duration of the follow-up period has an impact on the mortality levels of the hospitalised men and women due to selective mortality and cure. As we wanted to capture the immediate mortality development following hospital admission, we decided to use a relatively short follow-up period of 1-year length.

\section{Interpretation and implications in light of previous findings}

The existing literature focusing on the female mortality advantage has pointed towards the effects and the interactions of biological, behavioural and social factors. ${ }^{39}$ The most widely cited biological factors are hormonal, based on the observation that the female hormone oestrogen has favourable effects on serum lipid levels, as well as vasoprotective and immune-enhancing effects, and genetic, based on the assumption that women's second $\mathrm{X}$ chromosome helps to ameliorate the harmful effects of gene mutations on the $\mathrm{X}$ chromosome.$^{52-55}$ Moreover, women may have stronger immune systems than men, which could help women to recover more quickly, ${ }^{56}$ and may play a fundamental role in women's better survival of harsh conditions, including famines and epidemics. ${ }^{10}$ In addition to these biological factors, researchers have attributed a portion of the male disadvantage in mortality to behavioural and social factors. ${ }^{57}$ For example, it has been argued that men have higher rates than women of smoking, excessive drinking, drug use and violence.$^{58}$ In addition to this, a large body of previous research, including research for Denmark, has shown that men tend to seek medical help later than women, which can lead to delays in diagnosis and treatment. ${ }^{59-65}$ Previous studies have shown that men who are hospitalised tend to have conditions that are more severe and diseases are at more advanced stages than those of the women who are hospitalised; although the reasons for this pattern have not yet been fully understood. ${ }^{66}$ 
In Denmark, hospital care is financed through taxes, and is thus available to all residents, regardless of their sex and socioeconomic characteristics. ${ }^{67}$ Although our results may have been affected by changes in policies related to hospital admission, treatment and discharge, it is likely that such changes would have affected men and women in similar ways. Although access to healthcare services is free and universal in Denmark, individuals may encounter hurdles in accessing healthcare services for a variety of reasons, including social, economic, demographic and geographic factors. ${ }^{68}$ In Denmark, general practitioners (GPs) typically serve not just as gatekeepers for the use of secondary healthcare but also as care providers who can help patients avoid or postpone an admission to the hospital. For example, GPs assist patients in monitoring their health and in preventing the progress of many chronic conditions through regular medical check-ups, health consultations, the prescription of medications and other preventive measures. ${ }^{69}$ It is possible that the higher excess mortality after hospital admission among men, found in our study, may be partially explained by sex differences in health awareness and help-seeking long before an adverse health condition becomes visible. Thus, the female advantage in survival after hospital admission is likely to be due to multiple factors, including biological advantages underpinned by sex differences in health behaviours. Our findings point towards the importance of further research on the possibilities of an efficient primary healthcare system, as well as individuals' awareness of diseases, risk factors and compliance with preventive measures to reduce the male excess mortality following the manifestation of bad health.

\section{CONCLUSION}

In this study, we found that the risk of dying was highest for the hospitalised men and women in the 1-year period after admission to hospital, was lower among their counterparts in the general population and was lowest among those individuals who were not admitted to the hospital. We found the male excess mortality to be larger after the manifestation of bad health, which we measured as a hospital admission. Our findings point towards an association between the health status of a population and the magnitude of the absolute female advantage in mortality.

\author{
Author affiliations \\ ${ }^{1}$ Max Planck Institute for Demographic Research, Rostock, Germany \\ ${ }^{2}$ Department of Epidemiology, Biostatistics, and Biodemography, University of \\ Southern Denmark, Odense, Denmark \\ ${ }^{3}$ Department of Sociology and Demography, University of Rostock, Rostock, \\ Germany \\ ${ }^{4}$ Danish Aging Research Center, Odense, Denmark
}

Contributors $\mathrm{AH}, \mathrm{RL}-\mathrm{J}, \mathrm{RR}, \mathrm{KC}$ and $\mathrm{AO}$ designed the study. AH and LAL analysed the data. AH, LAL and DCS provided support to optimise the program code. AH, RL$\mathrm{J}, \mathrm{RR}, \mathrm{KC}$ and $\mathrm{AO}$ interpreted and discussed the results and implications. AH wrote the paper. All authors contributed to the revision of the paper and have approved the final version.
Funding The work was supported by the US National Institute of Health (P01AG031719, R01AG026786, and 2P01AG031719), the VELUX Foundation and the Max Planck Society within the framework of the project "On the edge of societies: New vulnerable populations, emerging challenges for social policies and future demands for social innovation. The experience of the Baltic Sea States (2016-2021)"

Disclaimer The funders had no role in the design of the study or in the collection, analysis, and interpretation of data and results.

Competing interests None declared.

Patient consent Not required.

Ethics approval The study involves secondary data analysis of existing register data. The project was approved by the ethical committee assigned through the Danish National Committee on Biomedical Research and the Danish Data Protection Agency.

Provenance and peer review Not commissioned; externally peer reviewed.

Data sharing statement No additional data are available.

Open access This is an open access article distributed in accordance with the Creative Commons Attribution Non Commercial (CC BY-NC 4.0) license, which permits others to distribute, remix, adapt, build upon this work non-commercially, and license their derivative works on different terms, provided the original work is properly cited, appropriate credit is given, any changes made indicated, and the use is non-commercial. See: http://creativecommons.org/licenses/by-nc/4.0/.

\section{REFERENCES}

1. Drevenstedt GL, Crimmins EM, Vasunilashorn $\mathrm{S}$, et al. The rise and fall of excess male infant mortality. Proc Natl Acad Sci U S A 2008;105:5016-21

2. Najari BB, Rink M, Li PS, et al. Sex disparities in cancer mortality: the risks of being a man in the United States. J Urol 2013;189:1470-4.

3. Edgren $\mathrm{G}$, Liang L, Adami HO, et al. Enigmatic sex disparities in cancer incidence. Eur J Epidemiol 2012;27:187-96.

4. Cook MB, McGlynn KA, Devesa SS, et al. Sex disparities in cancer mortality and survival. Cancer Epidemiol Biomarkers Prev 2011;20:1629-37.

5. de Torres JP, Cote CG, López MV, et al. Sex differences in mortality in patients with COPD. Eur Respir J 2009;33:528-35.

6. Dransfield MT, Washko GR, Foreman MG, et al. Gender differences in the severity of CT emphysema in COPD. Chest 2007;132:464-70.

7. Waldron I, McCloskey C, Earle I. Trends in gender differences in accidents mortality: Relationships to changing gender roles and other societal trends. Demogr Res 2005;13:415-54.

8. Stroebe M, Schut H, Stroebe W. Health outcomes of bereavement. Lancet 2007;370:1960-73.

9. Moon JR, Kondo N, Glymour MM, et al. Widowhood and mortality: a meta-analysis. PLoS One 2011;6:e23465.

10. Zarulli V, Barthold Jones JA, Oksuzyan A, et al. Women live longer than men even during severe famines and epidemics. Proc Natl Acad Sci U S A 2018;115:201701535.

11. Gjonça A, Tomassini C, Toson B, et al. Sex differences in mortality, a comparison of the United Kingdom and other developed countries. Health Stat Q 2005:6-16.

12. Wisser $\mathrm{O}$, Vaupel JW. The sex differential in mortality: a historical comparison of the adult-age pattern of the ratio and the difference. MPIDR Work Pap 2014:005.

13. Beltrán-Sánchez H, Finch CE, Crimmins EM. Twentieth century surge of excess adult male mortality. Proc Natl Acad Sci U S A 2015;112:8993-8.

14. Christensen K, Doblhammer G, Rau R, et al. Ageing populations: the challenges ahead. Lancet 2009;374:1196-208.

15. Karampampa K, Andersson T, Drefahl S, et al. Does improved survival lead to a more fragile population: time trends in second and third hospital admissions among men and women above the age of 60 in Sweden. PLoS One 2014;9:e99034.

16. Karampampa K, Drefahl S, Andersson T, et al. Trends in age at first hospital admission in relation to trends in life expectancy in Swedish men and women above the age of 60. BMJ Open 2013;3:e003447-54.

17. Case A, Paxson C. Sex differences in morbidity and mortality. Demography 2005;42:189-214.

18. Fleury MJ, Ngui AN, Bamvita JM, et al. Predictors of healthcare service utilization for mental health reasons. Int J Environ Res Public Health 2014;11:10559-86. 
19. Farkas J, Kosnik M, Flezar M, et al. Self-rated health predicts acute exacerbations and hospitalizations in patients with COPD. Chest 2010;138:323-30.

20. DeSalvo KB, Fan VS, McDonell MB, et al. Predicting mortality and healthcare utilization with a single question. Health Serv Res 2005;40:1234-46.

21. Kennedy BS, KasI SV, Vaccarino V. Repeated hospitalizations and self-rated health among the elderly: a multivariate failure time analysis. Am J Epidemiol 2001;153:232-41.

22. Hanlon $\mathrm{P}$, Lawder R, Elders A, et al. An analysis of the link between behavioural, biological and social risk factors and subsequent hospital admission in Scotland. J Public Health 2007;29:405-12.

23. Hanlon $P$, Walsh $D$, Whyte $B$, et al. The link between major risk factors and important categories of admission in an ageing cohort. $J$ Public Health 2000;22:81-9.

24. Hanlon P, Walsh D, Whyte BW, et al. Hospital use by an ageing cohort: an investigation into the association between biological, behavioural and social risk markers and subsequent hospital utilization. J Public Health Med 1998;20:467-76.

25. Smyth A, Teo KK, Rangarajan S, et al. Alcohol consumption and cardiovascular disease, cancer, injury, admission to hospital, and mortality: a prospective cohort study. Lancet 2015;386:1945-54.

26. Reeves GK, Balkwill A, Cairns BJ, et al. Hospital admissions in relation to body mass index in UK women: a prospective cohort study. BMC Med 2014;12:45.

27. Crowe FL, Appleby PN, Travis RC, et al. Risk of hospitalization or death from ischemic heart disease among British vegetarians and nonvegetarians: results from the EPIC-Oxford cohort study. Am J Clin Nutr 2013:97:597-603.

28. Garcia-Aymerich J, Lange P, Benet M, et al. Regular physical activity reduces hospital admission and mortality in chronic obstructive pulmonary disease: a population based cohort study. Thorax 2006;61:772-8.

29. Syddall HE, Westbury LD, Simmonds SJ, et al. Understanding poor health behaviours as predictors of different types of hospital admission in older people: findings from the Hertfordshire Cohort Study. J Epidemiol Community Health 2016;70:292-8.

30. Thygesen LC, Daasnes C, Thaulow I, et al. Introduction to Danish (nationwide) registers on health and social issues: structure, access, legislation, and archiving. Scand J Public Health 2011;39:12-16.

31. Pedersen CB. The Danish Civil Registration System. Scand J Public Health 2011;39:22-5.

32. Lynge E, Sandegaard JL, Rebolj M. The Danish National Patient Register. Scand J Public Health 2011;39:30-3.

33. Andersen TF, Madsen M, Jørgensen J, et al. The Danish National Hospital Register. A valuable source of data for modern health sciences. Dan Med Bull 1999;46:263-8.

34. Schmidt M, Pedersen L, Sørensen HT. The Danish Civil Registration System as a tool in epidemiology. Eur J Epidemiol 2014;29:541-9.

35. Hastie T, Tibshirani R. Generalized Additive Models. Statistical Science 1986;1:297-310.

36. Hastie T, Tibshirani R. Generalized additive models for medical research. Stat Methods Med Res 1995;4:187-96.

37. Wood S. Generalized additive models: an introduction with R: CRC press, 2006

38. Eilers PHC, Marx BD. Flexible smoothing with B -splines and penalties. Statistical Science 1996;11:89-121.

39. Oksuzyan A, Juel K, Vaupel JW, et al. Men: good health and high mortality. Sex differences in health and aging. Aging Clin Exp Res 2008;20:91-102.

40. Moser K, Frost $C$, Leon DA. Comparing health inequalities across time and place--rate ratios and rate differences lead to different conclusions: analysis of cross-sectional data from 22 countries 1991-2001. Int J Epidemiol 2007;36:1285-91.

41. Harper S, Lynch J. Methods for measuring cancer disparities: a review using data relevant to Healthy People 2010 cancer related objectives. Surveilance Monograph Series 2006;6.
42. Tramèr MR, Walder B. Number needed to treat (or harm). World $J$ Surg 2005;29:576-81.

43. Lindahl-Jacobsen R, Rau R, Jeune B, et al. Rise, stagnation, and rise of Danish women's life expectancy. Proc Natl Acad Sci U S A 2016;113:4015-20.

44. Lindahl-Jacobsen R, Oeppen J, Rizzi S, et al. Why did Danish women's life expectancy stagnate? The influence of interwar generations' smoking behaviour. Eur J Epidemiol 2016;31:1207-11.

45. Jacobsen R, Oksuzyan A, Engberg H, et al. Sex differential in mortality trends of old-aged Danes: a nation wide study of age, period and cohort effects. Eur J Epidemiol 2008;23:723-30.

46. Hubbard RE, Rockwood K. Frailty in older women. Maturitas 2011;69:203-7.

47. Eskes T, Haanen C. Why do women live longer than men? Eur J Obstet Gynecol Reprod Biol 2007;133:126-33.

48. Zhang Z, Fang J, Gillespie C, et al. Age-specific gender differences in in-hospital mortality by type of acute myocardial infarction. $\mathrm{Am} \mathrm{J}$ Cardiol 2012;109:1097-103.

49. Berger JS, Elliott L, Gallup D, et al. Sex differences in mortality following acute coronary syndromes. JAMA 2009;302:874-82.

50. Appelros P, Stegmayr B, Terént A. A review on sex differences in stroke treatment and outcome. Acta Neurol Scand 2010;121:359-69.

51. Appelros $\mathrm{P}$, Stegmayr B, Terént A. Sex differences in stroke epidemiology: a systematic review. Stroke 2009;40:1082-90.

52. Seifarth JE, McGowan CL, Milne KJ. Sex and life expectancy. Gend Med 2012;9:390-401.

53. Bouman A, Heineman MJ, Faas MM. Sex hormones and the immune response in humans. Hum Reprod Update 2005;11:411-23.

54. Stindl R. Tying it all together: telomeres, sexual size dimorphism and the gender gap in life expectancy. Med Hypotheses 2004;62:151-4.

55. Christensen K, Ørstavik KH, Vaupel JW. The X Chromosome and the female survival advantage. Ann N Y Acad Sci 2001;954:175-83.

56. Oertelt-Prigione $S$. The influence of sex and gender on the immune response. Autoimmun Rev 2012;11:A479-A485.

57. Rieker PP, Bird CE. Rethinking gender differences in health: why we need to integrate social and biological perspectives. $J$ Gerontol $B$ Psychol Sci Soc Sci 2005;60:S40-S47.

58. Rogers RG, Everett BG, Onge JM, et al. Social, behavioral, and biological factors, and sex differences in mortality. Demography 2010;47:555-78.

59. Farrimond $\mathrm{H}$. Beyond the caveman: Rethinking masculinity in relation to men's help-seeking. Health 2012;16:208-25.

60. Chan RKH, Hayashi K. Gender roles and help-seeking behaviour promoting professional help among Japanese men. J Soc Work 2010;10:243-62.

61. Juel K, Christensen K. Are men seeking medical advice too late? Contacts to general practitioners and hospital admissions in Denmark 2005. J Public Health 2008;30:111-3.

62. Noone JH, Stephens C. Men, masculine identities, and health care utilisation. Sociol Health IIIn 2008;30:711-25.

63. Adeyemi SA. Men's health help-seeking and implications for practice. Am J Heal Stud 2007;22:88.

64. Smith JA, Braunack-Mayer A, Wittert G. What do we know about men's help-seeking and health service use? Med J Aust 2006;184:81.

65. Smith LK, Pope C, Botha JL. Patients' help-seeking experiences and delay in cancer presentation: a qualitative synthesis. Lancet 2005;366:825-31.

66. Simmonds SJ, Syddall HE, Walsh B, et al. Understanding NHS hospital admissions in England: linkage of Hospital episode statistics to the hertfordshire cohort study. Age Ageing 2014;43:653-60.

67. Olesen F, Hansen RP, Vedsted P. Delay in diagnosis: the experience in Denmark. Br J Cancer 2009;101:S5-S8.

68. Starfield B, Gérvas J, Mangin D. Clinical care and health disparities. Annu Rev Public Health 2012;33:89-106.

69. Gérvas J, Starfield B, Heath I. Is clinical prevention better than cure? Lancet 1997;2008:372. 